\title{
A novel gene from a secondary metabolism gene cluster is required for microsclerotia formation and virulence in Verticillium dahliae
}

\author{
Dianguang Xiong, Yonglin Wang and Chengming Tian ${ }^{*}$
}

\begin{abstract}
Verticillum dahliae is a notorious plant pathogenic fungus, which can cause wilt disease on hundreds of plant species. The genome of $V$. dahliae has been sequenced and annotated, but incorrect gene annotations and unidentified transcribed regions persist. Using RNA-Seq combined with reverse-transcription PCR, we identified a novel transcribed gene, Nag1, located in a cluster of putative secondary metabolic genes whose roles remain unknown. Functional analysis of Nagl by dsRNA-mediated gene silencing revealed that loss of Nagl significantly decreased fungal growth and conidial production. In addition, Nag1-silenced mutants exhibited obvious defects in microsclerotia formation and fungal virulence. Consistent with the reduction in microsclerotia formation, melanin production and expression of genes involved in melanin biosynthesis were markedly reduced in Nag1-silenced mutants. Overall, our data suggest that Nag1 acts as an important regulator of fungal development, microsclerotia formation and secondary metabolism in $V$. dahliae.
\end{abstract}

Keywords: Novel transcript region, RNAi-mediated silencing, Melanin biosynthesis

\section{Background}

Verticillium dahliae Kleb., the causal agent of Verticillium wilt disease, is a notorious pathogenic fungus that can infect more than 200 plant species and result in enormous economic loss all over the world (Fradin and Thomma 2006; Klosterman et al. 2009). Due to the pathogen's ability to colonize the xylem and the longevity of microsclerotia, no effective control methods for Verticillium wilt disease are available (Wilhelm 1955). Microsclerotia are melanized resting structures formed by $V$. dahliae that play critical roles during the disease cycle (Puhalla and Bell 1981; Klimes et al. 2015). Upon encountering a suitable host, microsclerotia germinate into hyphae and infect plants through the roots (Klimes et al. 2015). However, the mechanisms underlying microsclerotia development in $V$. dahliae remain to be elucidated.

Recent advances in sequencing technology have greatly facilitated functional genomics research. RNA-Seq is a

* Correspondence: chengmt@bju.edu.cn

The Key Laboratory for Silviculture and Conservation of Ministry of Education, College of Forestry, Beijing Forestry University, Beijing, China powerful technology for examining changes in transcriptional profiles under various conditions (Wang et al. 2009), and can also be used to improve annotation of gene models and detect novel transcribed regions (Roberts et al. 2011). In addition, alternative splicing and RNA editing events can also be identified by taking advantage of RNA-Seq technology (Pan et al. 2008; Peng et al. 2012).

RNA interference (RNAi), also known as gene silencing, is a natural phenomenon observed in plants, fungi, and animals. This phenomenon plays diverse roles in genomic defense, heterochromatin formation, and gene regulation (Agrawal et al. 2003; Matzke and Birchler 2005). RNAi, a post-transcriptional mode of regulation, decreases the expression of target genes by degrading mRNA with homologous double-stranded RNA (dsRNA) (Fire et al. 1998). This method has been developed as a useful tool for genetic manipulation, and has been successfully used for analysis of gene functions in all kinds of organisms. In contrast to gene knockout technology, RNAi can be used to characterize the

(c) The Author(s). 2019 Open Access This article is distributed under the terms of the Creative Commons Attribution 4.0 International License (http://creativecommons.org/licenses/by/4.0/), which permits unrestricted use, distribution, and reproduction in any medium, provided you give appropriate credit to the original author(s) and the source, provide a link to the Creative Commons license, and indicate if changes were made. The Creative Commons Public Domain Dedication waiver (http://creativecommons.org/publicdomain/zero/1.0/) applies to the data made available in this article, unless otherwise stated. 
functions of multi-copy and essential genes. In filamentous fungi, three well-known RNAi strategies can be used to manipulate the expression of a target gene: expression of a hairpin RNA, production of dsRNA by convergent transcription, and direct introduction of dsRNA into fungal cells (Khatri and Rajam 2007; Nakayashiki and Nguyen 2008; Li et al. 2010). In general, the former two methods (expression of a hairpin RNA and production of dsRNA by convergent transcription) are much more efficient. However, expression of hairpin RNA is time-consuming and not well suited for high-throughput analysis, whereas production of dsRNA by convergent transcription can be easily manipulated and facilitates large-scale functional analysis. The functions of 37 calcium-signaling genes in Magnaporthe oryzae were characterized using a convergent transcription approach (Nguyen et al. 2008), and ten endo- $\beta-1,4$ xylanase genes were simultaneously silenced in M. oryzae using a similar strategy (Nguyen et al. 2011). Furthermore, RNAi method (expression of a hairpin RNA) has been used to analyze the functions of the chorismate synthase encoded gene (Singh et al. 2010) and the $\mathrm{C}_{2} \mathrm{H}_{2}$ transcription factor gene Vta2 (Tran et al. 2014) in the near-diploid fungus Verticillium longisporum, indicating that RNAi is suitable for use in Verticillium species.

Secondary metabolites are often bioactive but not essential for fungal survival (Keller et al. 2005). The most famous secondary metabolite is penicillin, which has saved hundreds of millions of human lives (Bennett and Chung 2001). By contrast, some fungal secondary metabolites are poisonous, such as Fumonisin B1 in Fusarium verticillioides (Wang et al. 1991; Nelson et al. 1993). Polyketides, non-ribosomal peptides, terpenes, and indole alkaloids are representative examples of fungal secondary metabolites, and the genes responsible for their biosynthesis are usually arranged in clusters (Keller et al. 2005; Fox and Howlett 2008). Melanin, a type of polyketide, is one of the most common secondary metabolites produced by fungi, and it has functions in cell wall stability and facilitating survival in hostile environments (Nosanchuk and Casadevall 2003). In fungi, melanin is synthesized via two main pathways: the L-3-4-dihydroxyphenylalanine pathway, in which dihydroxyphenylalanine is oxidized by laccase and polymerized into melanin, as in Cryptococcus neoformans (Eisenman et al. 2007; Eisenman et al. 2009); and the 1, 8-dihydroxynaphthalene (DHN) pathway, which is operative in $V$. dahliae (Bell et al. 1976; Stipanovic and Bell 1976; Wheeler et al. 1976). Melanin is generated during microsclerotia formation in $V$. dahliae, and several genes involved in this process have been identified (Duressa et al. 2013; Xiong et al. 2014; Fang et al. 2019). Other pathogenic fungal species, including M. oryzae (Soanes et al. 2012) and Sporothrix schenckii (RomeroMartinez et al. 2000), also produce melanin through the DHN pathway.
In this study, we identified a previously overlooked gene (Nag1) in the $V$. dahliae genome and characterized its functions by the dsRNA-induced gene silencing approach. The resultant Nag1-silenced mutants exhibited obvious defects in fungal growth, conidial production, fungal virulence, and microsclerotia formation. Additionally, the production of melanin was significantly reduced in Nag1-silenced mutants, and the expression levels of genes involved in this process were also reduced.

\section{Results}

\section{Identification of a new annotated gene from RNA-Seq data}

Our previous transcriptomic analysis revealed hundreds of novel transcribed regions that did not match any annotated gene models (Xiong et al. 2014) (Data not shown). In this study, we focused on a novel transcribed region between VDAG_07930 and VDAG_07931. The transcript derived from this region, $\sim 1500 \mathrm{bp}$ in length, is encoded on the "-" strand of scaffold 18, whereas VDAG_07930 and VDAG_07931 are located on the "+" strand (Fig. 1a). RNA-Seq coverage data indicated that the transcript was expressed at relatively high levels during all developmental stages studied (Fig. 1a). The structural model of assembled reads suggests that this transcript is derived from a novel gene consisting of two exons and one intron (Fig. 1a). The longest open reading frame (ORF), $993 \mathrm{bp}$ in length, was predicted by submitting the sequence of the novel transcript (from supercontig_1.18, positions 440,477 to 441,866 , with or without the putative intron sequence) to ORF Finder (http://www.ncbi.nlm.nih.gov/gorf/gorf.html) (Fig. 1b). Remarkably, this ORF could be amplified from cDNA of $V$. dahliae XS11 and Ls17 (Fig. 1c), and sequencing revealed that the ORF from $V$. dahliae XS11 perfectly matched that from $V$. dahliae Ls17. In addition, the location of the intronic sequences (positions 441,604-441, 659) was correctly predicted by the RNA-Seq assembly. The redundant sequences at both ends of the ORF were regarded as untranslated regions (Fig. 1b).

Based on these findings, we considered this novel transcribed region as a new annotated gene, Nag1, consisting of two exons and one intron (exon 1: 441660-441,756, intron: 441604-441,659, exon 2: 440708-441,603). Nag1 encodes a protein of 330 amino acids with no detectable structural motifs other than a DUF3425 (protein of unknown function) domain (Additional file 1: Figure S1 and Fig. 1d). Remarkably, the complete sequence of Nag1 is also present in the genome of $V$. dahliae JR2, with 100\% sequence identity.

\section{Identification of Nag1 homologs in other fungal species}

To identify Nag1 homologs in other fungal species, we searched fungal genomes using the amino acid or 


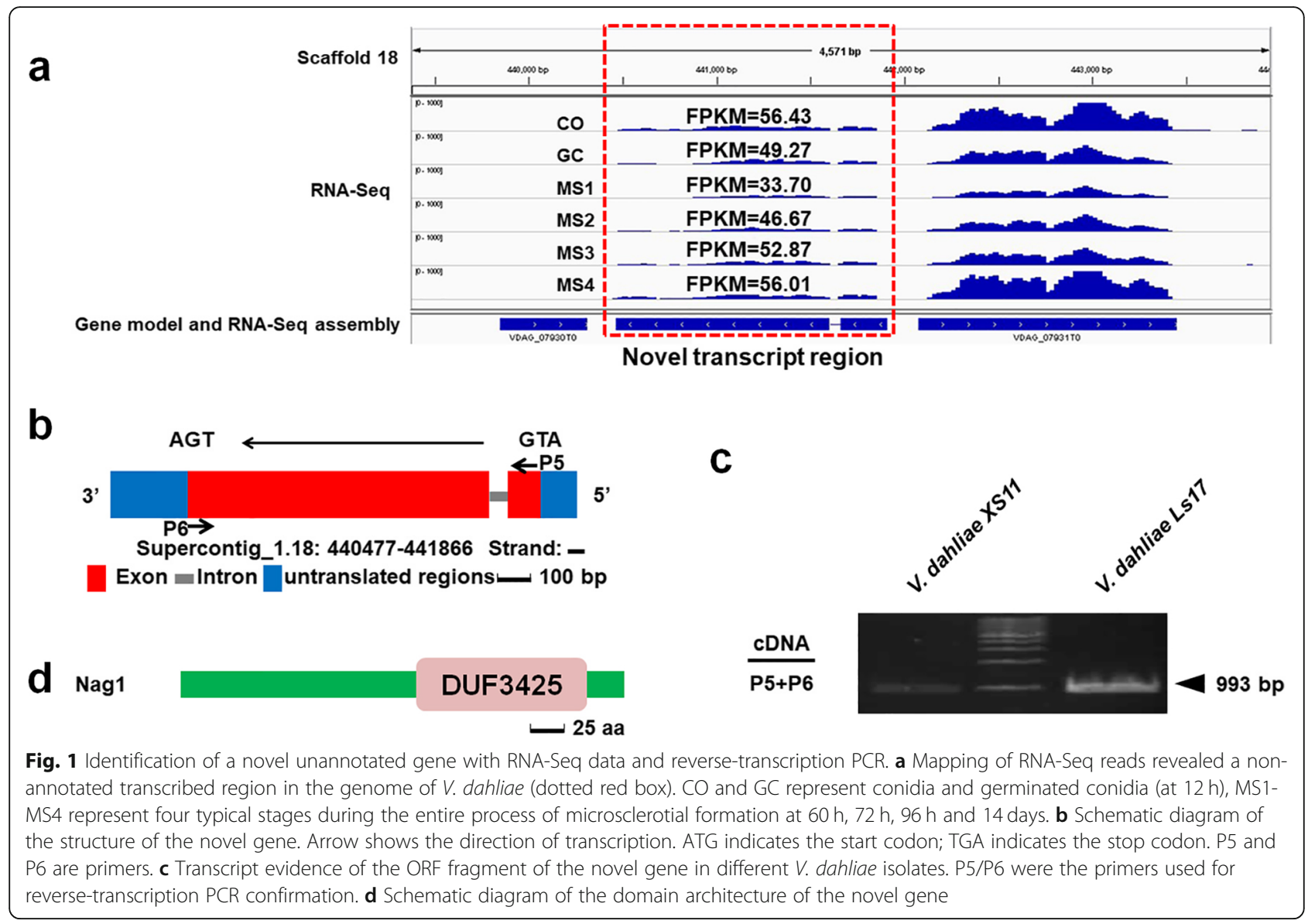

nucleotide sequence of Nag1 as a query. BLASTP searches detected putative Nag1 homologs in several fungal species, including Aspergillus niger (NRRL3_ 01662), M. oryzae (MGG_14540) and Fusarium oxysporum (FOXG_09755), but no homologs were found in Ustilago maydis, Schizosaccharomyces pombe, Saccharomyces cerevisiae, or Neurospora crassa (Fig. 2a). With the exception of VDBG_07836, all putative Nag1 homologs contained a DUF3425 domain near their C-termini (Fig. 2a). By contrast, BLASTN searches detected homologous sequences only in $A$. niger NRRL3, $V$. alfalfae, and F. verticillioides 7600 genomes (Fig. 2a). Multiple nucleotide sequence alignment of Nag1 and its homologous sequences from these three strains revealed that the sequences from $V$. dahliae, $A$. niger NRRL3, and $V$. alfalfae were highly similar, especially between the $V$. dahliae and $V$. alfalfae which shared almost $90 \%$ sequence identity (Additional file 2: Figure S2). However, only the homologous nucleotide sequences in $A$. niger NRRL3 corresponded to a protein-coding gene NRRL3 01662, which was consistent with the results acquired from the BLASTP search. Therefore, we regarded NRRL3_01662 as a candidate Nag1 ortholog. Amino acid sequence alignment of Nag1 and NRRL3_01662 revealed that the two proteins share $51 \%$ sequence identity (Fig. 2b). Furthermore, candidate Nag1 orthologs were also found in the genomes of $A$. niger CBS (An01g00950m) and A. niger ATCC (MIX4101_1_6). However, the homologous nucleotide sequences in $V$. alfalfae and F. verticillioides 7600 were located in unannotated regions, indicating that unidentified candidate Nag1 orthologs may also exist in the genomes of $V$. alfalfae and F. verticillioides 7600, particularly in the former.

\section{RNAi-mediated down-regulation of Nag1 impairs fungal growth}

The dsRNA-mediated gene silencing approach was used to analyze the functions of Nag1 in $V$. dahliae, which had been tested by GFP fluorescence (Data not shown). In particular, we used a $417 \mathrm{bp}$ specific fragment of Nag1 to target the gene for silencing. Quantitative realtime PCR (qRT-PCR) revealed that two transformants, Nag1-S3 and Nag1-S6, exhibited $>50 \%$ reduction in gene expression (Fig. 3). Accordingly, these transformants were selected for further analysis.

Nag1-S3 and Nag1-S6 grew significantly $(P \leq 0.05)$ more slowly than the wild-type strain (Fig. $4 a, b)$. Of the 


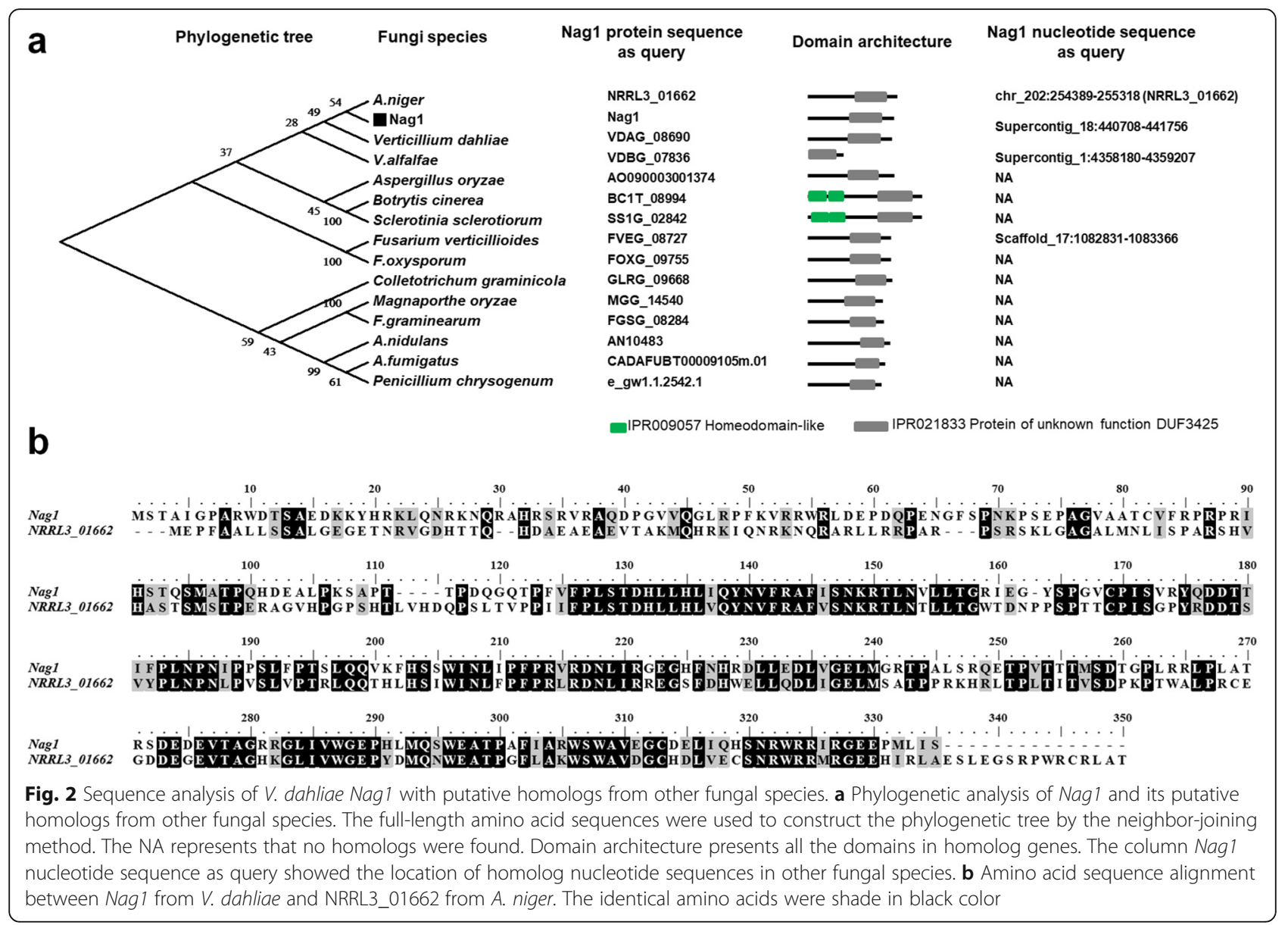

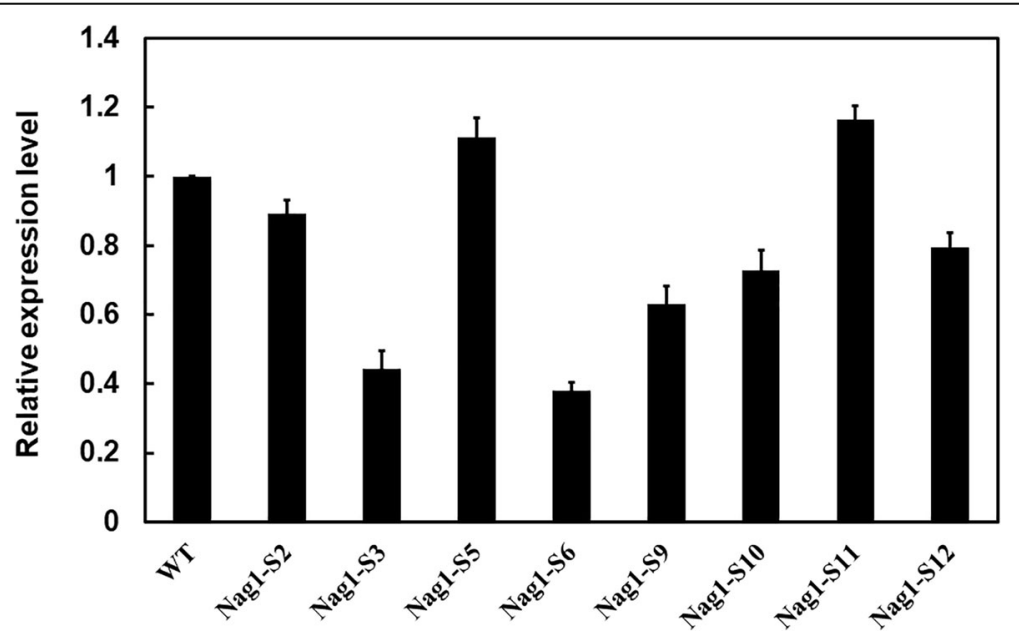

Fig. 3 Identification of Nag1-silenced mutants in V. dahliae. Transcript abundance was measured by qRT-PCR and normalized against an endogenous control, $\beta$-tubulin. Error bars indicate standard deviation from three independent experiments 

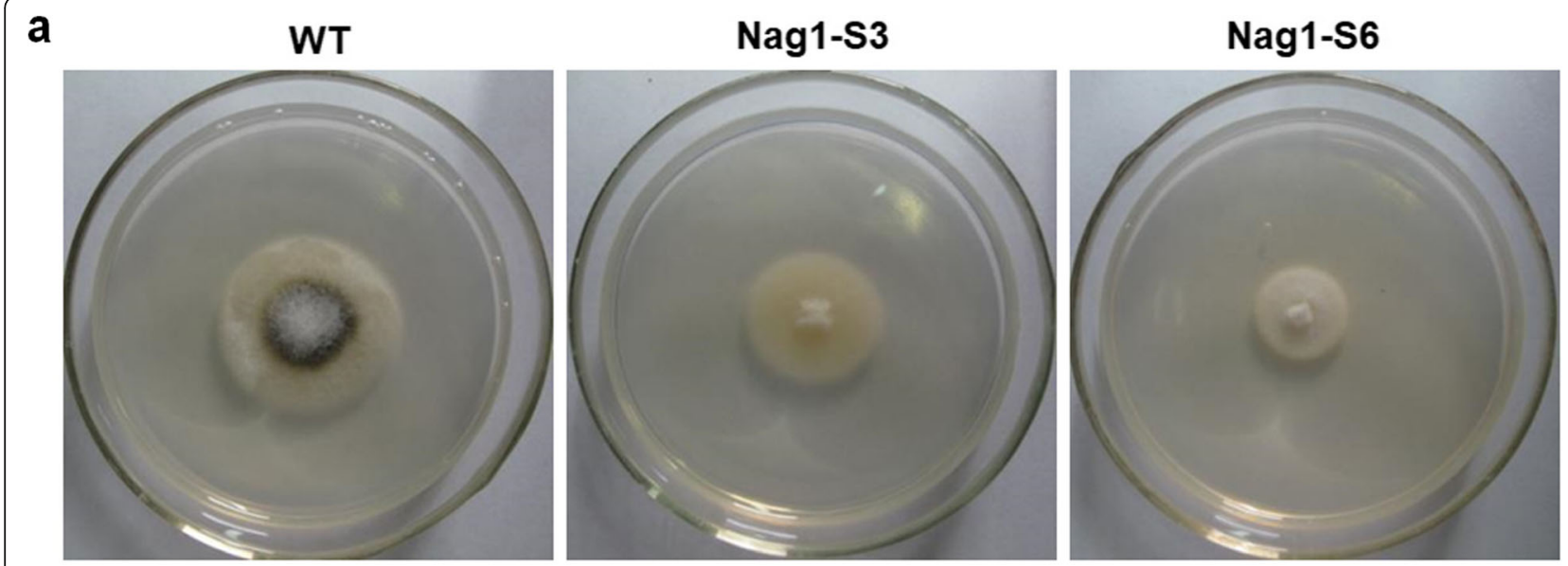

b

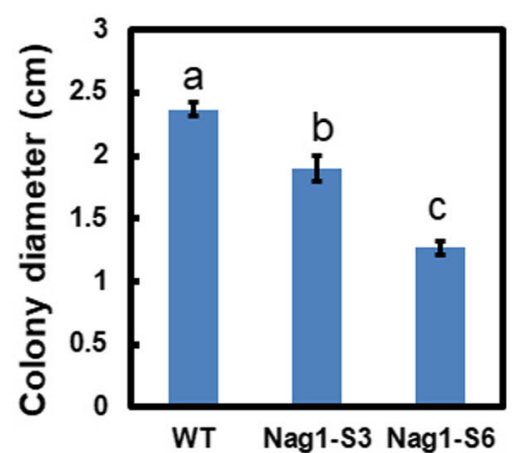

C

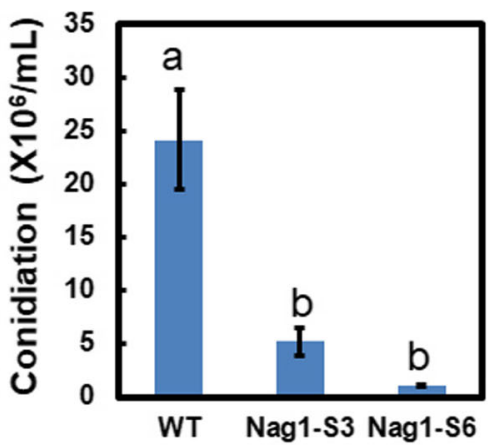

d

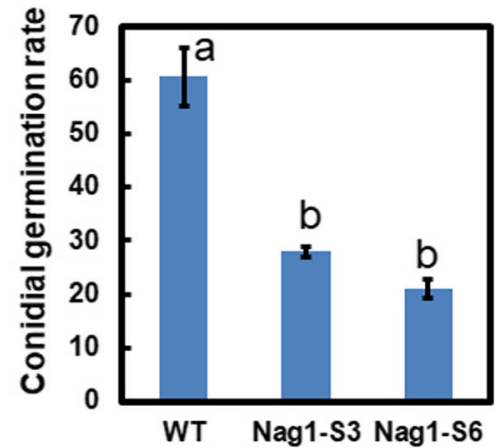

Fig. 4 Silencing of Nag1 causes delayed growth and reduced conidial production and germination. a Colony morphology of the wild-type strain (WT) and two Nag1-silenced mutants. The pictures were taken at $7 \mathrm{dpi}$ on PDA plates at room temperature. $\mathbf{b}$ Colony diameter statistics of WT, Nag1-S3, and Nag1-S6 at 7 dpi on PDA plates at room temperature. Error bars were derived from three independent experiments. c Number of conidia produced by WT, Nag1-S3, and Nag1-S6 at 8 dpi on PDA plates at room temperature. Error bars were derived from three independent experiments. $\mathbf{d}$ The percentage of conidial germination after 2 days of growth in liquid BM at 150 rpm at $25^{\circ} \mathrm{C}$. Error bars indicate standard deviation from three independent experiments. Different letters in (b), (c), (d) indicate significant differences at $P \leq 0.05$

two mutants, Nag1-S6 grew much more slowly than Nag1-S3 (the colony diameter of Nag1-S6 was about $60 \%$ of Nag1-S3), consistent with the relative Nag1 expression levels in the two strains (Fig. 3 and Fig. 4a). No melanin was visible in either Nag1-S3 or Nag1-S6, whereas the pigment clearly accumulated in wild-type colonies (Fig. 4a). In addition, Nag1-S3 and Nag1-S6 mutants exhibited a dramatic reduction in conidial production (78.4 and $95.7 \%$ reduction relative to the wild type, respectively) (Fig. 4c). Conidial production was also obviously reduced in Nag1-silenced mutants growing in liquid CM (Additional file 3: Figure S3). Furthermore, silencing of Nag1 significantly decreased conidial germination with 32 and $39 \%$ reduction in Nag1-S3 and Nag1-S6 conidial germination rates compared with the wild type, respectively (Fig. 4c). These results indicated that Nag1 is involved in fungal growth, conidial production, and germination in V. dahliae.

\section{Nag1 is involved in cell wall integrity}

To determine the role of Nag1 in cell wall integrity, all strains were inoculated onto standard $\mathrm{CM}$ plates (control) or $\mathrm{CM}$ containing $\mathrm{NaCl}, \mathrm{KCl}, \mathrm{MgSO}_{4}$, Calcofluor White (CFW), and Congo Red. At 10 days post inoculation (dpi), colony diameters were significantly reduced on the supplemented plates relative to the control plates, especially on $\mathrm{NaCl}$ and $\mathrm{KCl}$ supplemented plates, which reduced growth diameter of Nag1-silenced mutants and wild type by over $50 \%$ compared with the strains grown on the CM plates, respectively (Additional file 4: Figure S4). Nag1-S3 and Nag1-S6 exhibited slightly higher resistance to $\mathrm{NaCl}, \mathrm{KCl}$, and $\mathrm{MgSO}_{4}$ than the wild-type strain, which showed higher relative growth in Nag1-silenced mutants (over $40 \%$ relative growth in $\mathrm{NaCl}, \mathrm{KCl}$ and $92 \%$ relative growth in $\mathrm{MgSO}_{4}$ relative to the CM plates) compare to wild type $(36.6 \%$ relative growth in $\mathrm{NaCl}, \mathrm{KCl}$ and $87 \%$ relative growth in $\mathrm{MgSO}_{4}$ relative to the CM plates) (Additional file 4: Figure S4a, b). These 
results indicated that silencing of Nag1 slightly decreased sensitivity to osmotic stresses. We also investigated the sensitivity of all three strains to oxidative stress $\left(5 \%\right.$ or $\left.15 \% \mathrm{H}_{2} \mathrm{O}_{2}\right)$, but observed no distinguishable difference in the size of the inhibition zone (Additional file 4: Figure S4c), indicating that Nag1 is not required for resistance to $\mathrm{H}_{2} \mathrm{O}_{2}$.

\section{Silencing of Nag1 dramatically decreases microsclerotia formation}

Nag1-silenced transformants exhibited a significant delay and reduction in microsclerotia formation relative to the wild-type strain. As described previously, visible melanized microsclerotia formed in the wild-type strain at $60 \mathrm{~h}$ post inoculation (hpi) on a cellulose membrane (Xiong et al. 2014). By contrast, Nag1-S3 exhibited no clear changes until $108 \mathrm{hpi}$. At that time point, a spot of slightly melanized microsclerotia could be observed on plates of Nag1-S3; by contrast, in the wild-type strain, large numbers of melanized microsclerotia had formed (Fig. 5a). In both strains, microsclerotia formation continued to progress at $6 \mathrm{dpi}$, but many more microsclerotia were formed on the plates containing the wild-type strain (Fig. 5a). The melanized microsclerotia were obviously formed in both wild-type strain and Nag1-S3 after 12 days of incubation, but the microsclerotia formation was still dramatically compromised in Nag1-S3 compared with wild-type strain (Fig. 5a).

We also observed the early development of microsclerotia by scanning electron microscopy. In the wild-type strain, massive mycelia formed and covered the cellulose membrane, and aerial mycelia formed at 36 hpi. By 48 hpi, we could observe formation of swollen mycelia, which gathered to generate microsclerotia between 60 and 72 hpi (Fig. 5b). By contrast, Nag1-S3 did not form the aerial mycelia and swollen mycelia from 36 to $72 \mathrm{hpi}$. It took $60 \mathrm{~h}$ for Nag1-S3 to cover the cellulose membrane, and aerial conidiophores developed at $72 \mathrm{hpi}$ (Fig. $5 \mathrm{~b})$. Thus, the developmental processes of microsclerotia were delayed about 2 days in Nag1-S3 relative to the wild-type strain, largely resulting from defects in fungal growth. These results suggested that Nag1 plays an important role in microsclerotia formation (Fig. 5).

\section{Silencing of Nag1 decreases fungal virulence}

To investigate the pathogenicity of Nag1-silenced mutants, we inoculated the roots of 1-year-old smoke tree seedlings with conidial suspensions of the wild type, Nag1-S3, and Nag1-S6. In consideration of the significantly reduced fungal growth in the mutants, the time period that symptoms were monitored was extended to 45 days. As expected, no obvious wilt symptoms were observed in plants infected with Nag1-S3 and Nag1-S6 whereas the plants inoculated with the wild-type strain

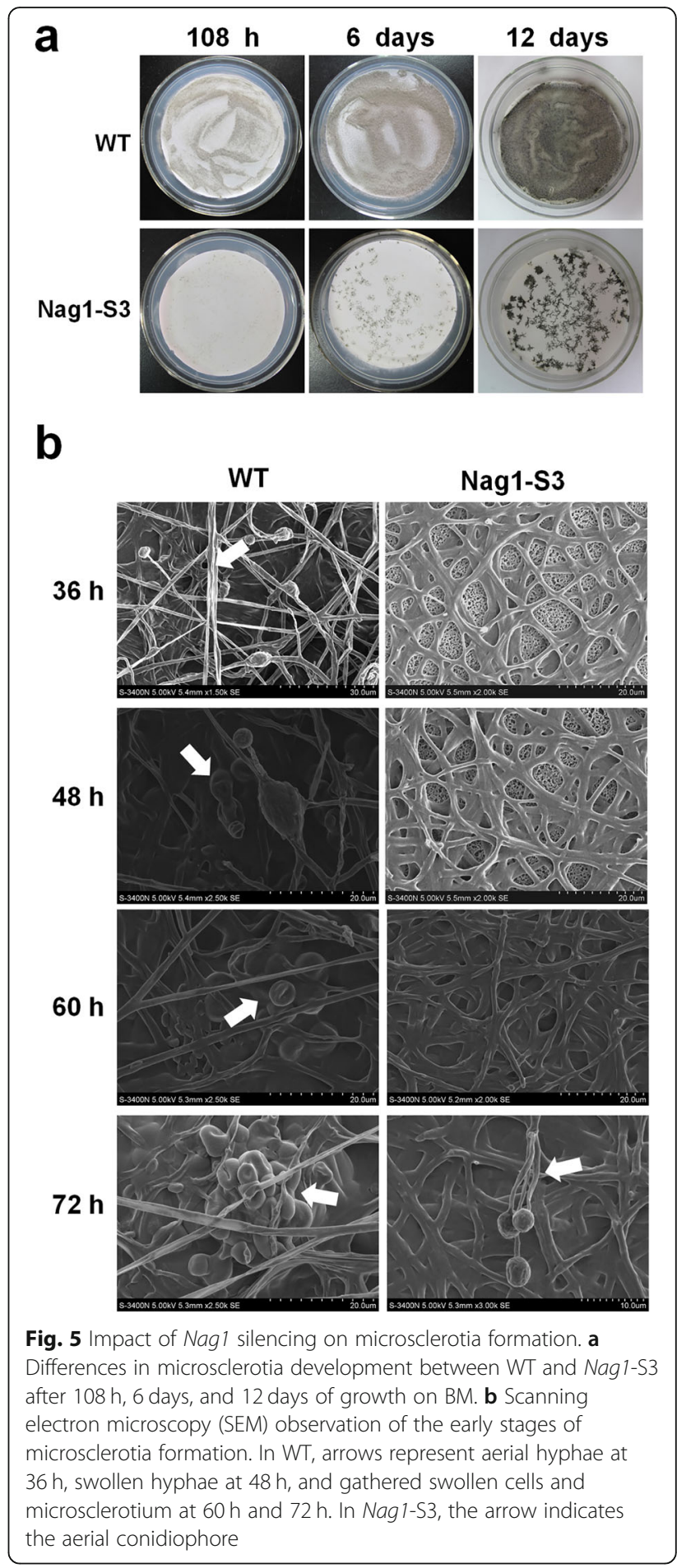

exhibited strong Verticillium wilt (Fig. 6). The results suggested that Nag1 is involved in fungal virulence.

\section{Silencing of Nag1 significantly decreases melanin biosynthesis}

Nag1-silenced mutants exhibited obvious defects in melanin accumulation on PDA plates (Fig. 4a). 

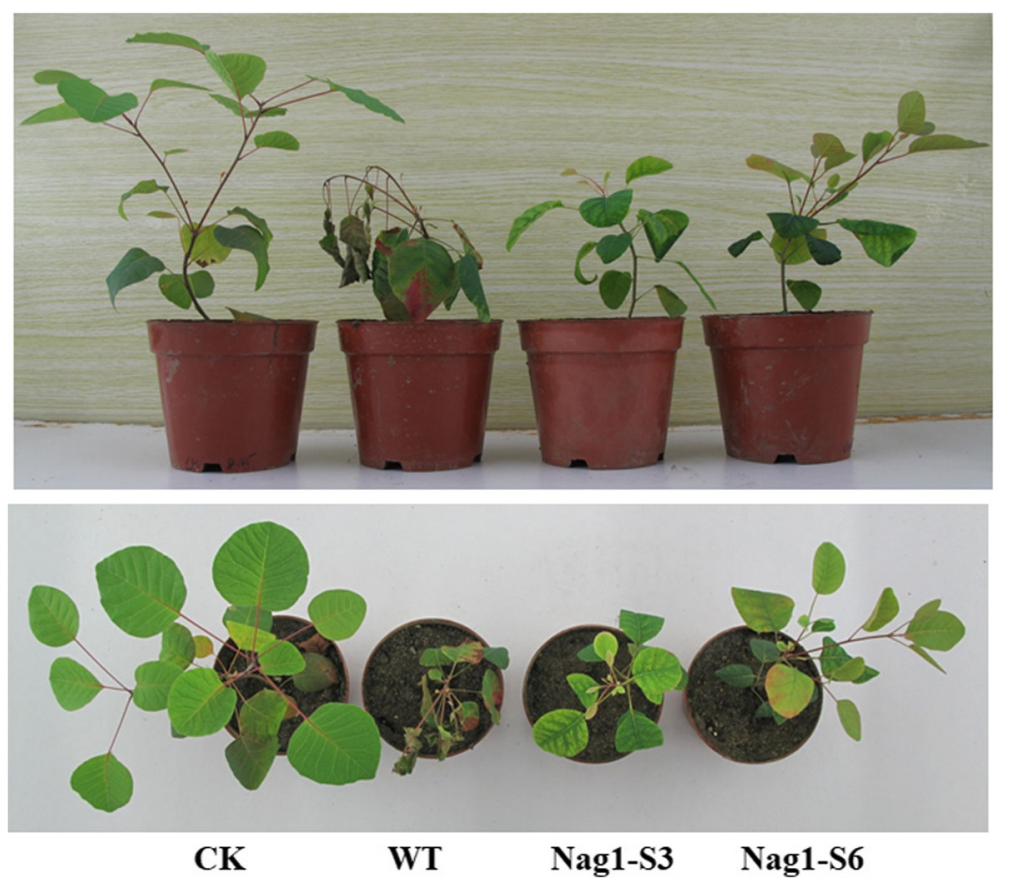

Fig. 6 Silencing of Nag1 reduces fungal pathogenicity. Side and top views of 1-year-old smoke tree seedlings inoculated with $10^{6} \mathrm{spores} / \mathrm{mL}$ conidial suspension of WT, Nag1-S3, or Nag1-S6 for 10 min. Smoke tree seedlings mock-inoculated with distilled water were used as controls. Pictures were taken at $45 \mathrm{dpi}$

Subsequently, we investigated the production of melanin in Nag1-silenced mutants grown in Czapek-Dox salts medium. Melanin obviously accumulated in the wildtype strain, whereas no visible melanin could be observed in either Nag1-S3 or Nag1-S6 after 7 days of shaking culture (Fig. 7a). To further elucidate the differences in melanin production among the three strains, the cultures were grown in Czapek-Dox salts medium for another 7 days. Much more melanin was produced in the wild-type strain at 14 days than at 7 days (Fig. 7a). By contrast, very little melanin was observed in Nag1-S3, and no visible melanin was produced in Nag1-S6, after 14 days of growth (Fig. 7a). These results suggested that silencing of Nag1 led to dramatic defects in melanin production. In addition, we determined the transcript levels of several genes involved in the DHN pathway (VDAG_00183, VDAG_00190, VDAG_03393, VDAG_ 03674, VDAG_03665) or pigment synthesis (VDAG_ 00186, VDAG_00189, VDAG_00192, VDAG_04594, VDAG_05181). Consistent with the phenotypic observations, expression of all of these genes was significantly lower in Nag1-S3 and Nag1-S6 than in the wild-type strain, several of them (VDAG_00190, VDAG_03665, VDAG_03674, VDAG_04594) reduced their expression by $\sim 50 \%$ in Nag1-silenced mutants, and two of them (VDAG_00189 and VDAG_03393) had expression reductions by $\sim 80 \%$ in Nag1-silenced mutants (Fig. 7b).
These results indicated that Nag1 plays important roles in melanin production.

\section{Silencing of Nag1 decreases expression of secondary metabolism genes}

Secondary metabolism genes and gene clusters have been identified in the genome sequence of $V$. dahliae (Xiong et al. 2016; Shi-Kunne et al. 2019). According to these data, Nag1 is located in a PKS/NRPS hybrid secondary metabolism gene cluster containing genes from VDAG_07920 to VDAG_07931. These results indicate that Nag1 is a secondary metabolism gene. We subsequently examined the expression levels of other genes in this cluster, and the results revealed that all genes in this cluster significantly reduced their expression levels in Nag1-silenced mutants, especially in genes from VDAG 07920 to VDAG_07928 (over 90\% reduction in transcript levels) (Fig. 8). Our data indicated that silencing of Nag1 decreased expression of genes in the same secondary metabolism cluster, suggesting that genes in the same cluster might share similar expression patterns. Additionally, we showed in previous work that expressions of genes in the PKS/NRPS hybrid secondary metabolism gene cluster are regulated by the MADS-box transcription factor gene $V d M c m 1$ (Xiong et al. 2016). Accordingly, as expected, both RNA-Seq and qRT-PCR assays indicated that Nag1 was transcribed at lower 


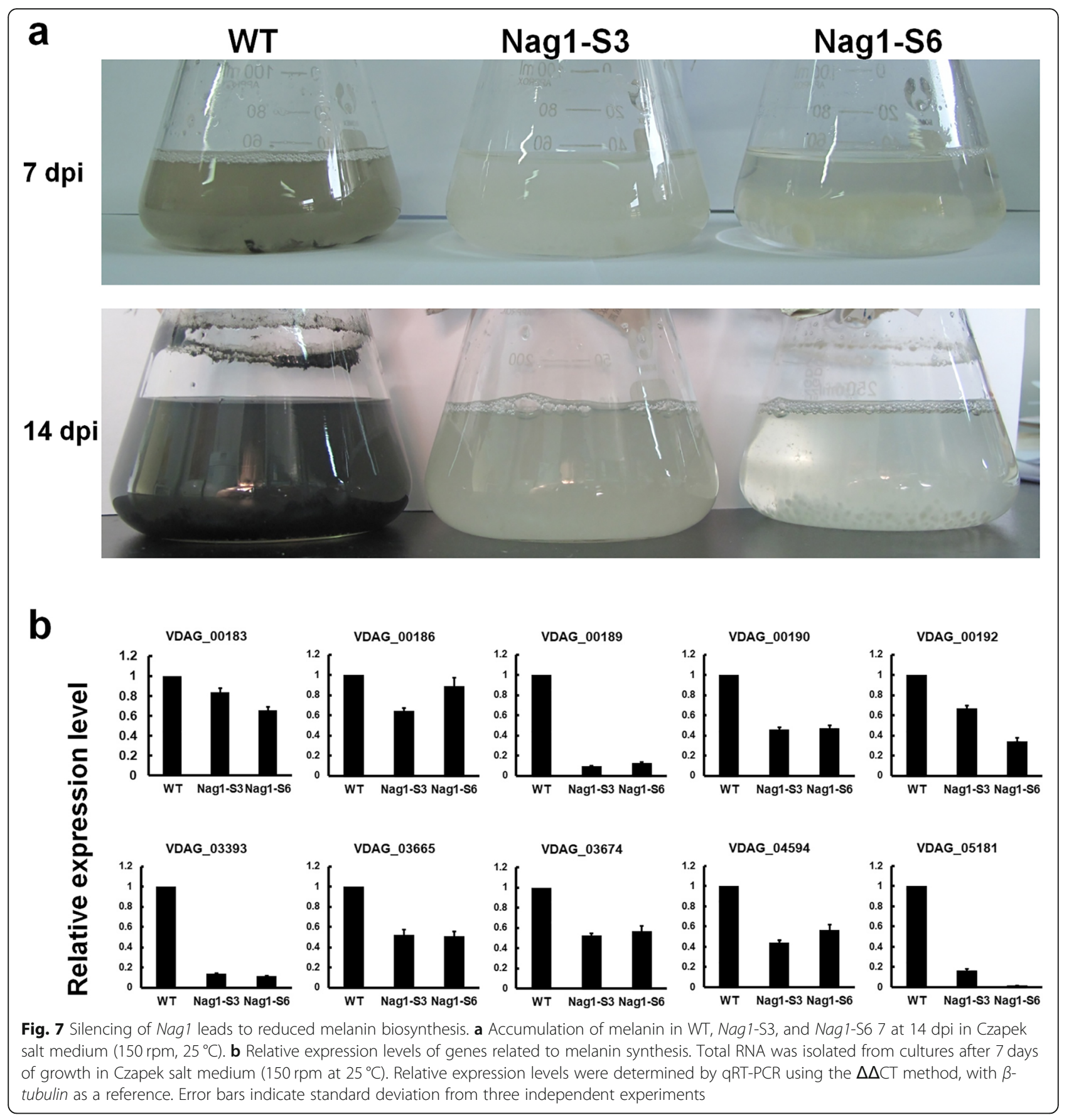

levels in the $V d M c m 1$ deletion mutant than in the wildtype strain (Additional file 5: Figure S5).

\section{Discussion}

As a result of technical advances and cost reductions in sequencing, more and more species have been sequenced. To improve genome annotations and reveal specific features of various isolated strains, an increasing number of species have also been re-sequenced, yielding a large body of sequence data and annotated gene models. However, achieving correct gene annotation remains a challenge. Generally, prediction of gene models is performed by machine annotation with FGENESH, GENEID, and other bioinformatic tools (Cuomo et al. 2007; Klosterman et al. 2011). However, many of these annotations lack transcriptional evidence, and some gene model predictions are inaccurate, especially in the case of species-specific and non-conserved genes. Additionally, it is relatively difficult to distinguish novel genes and untranslated regions by bioinformatic prediction 


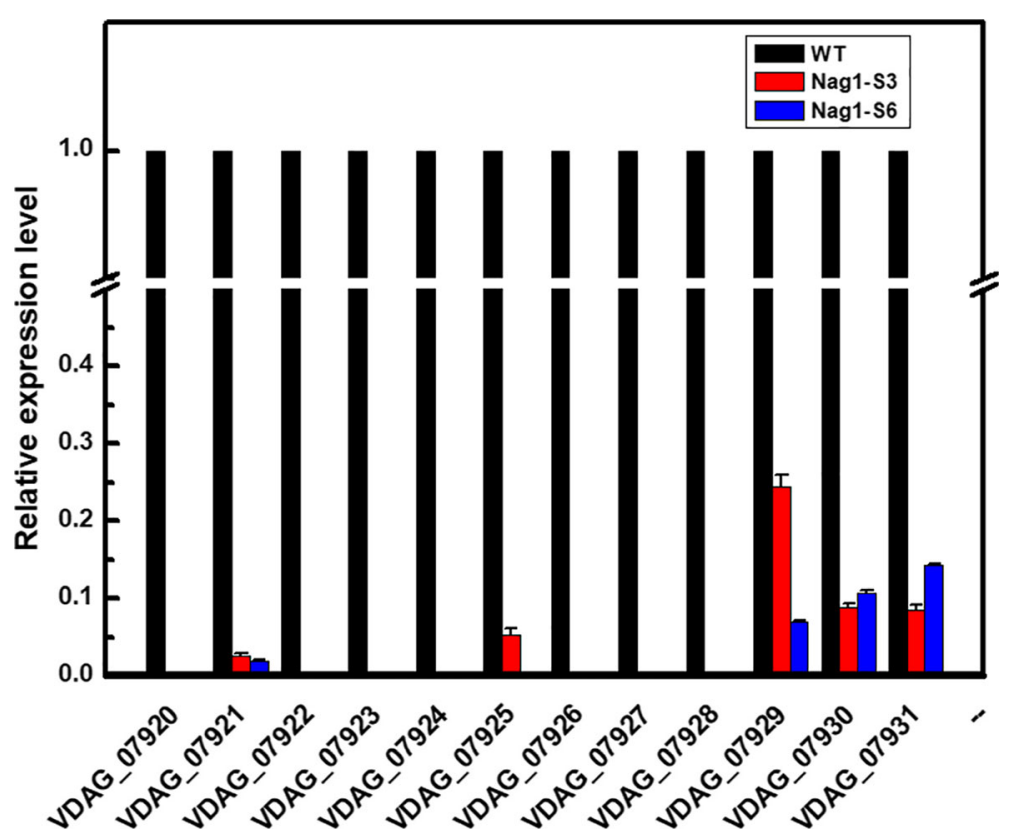

Fig. 8 Silencing of Nag1 induces down-regulation of putative secondary metabolism genes. Expression levels of putative secondary metabolism genes in WT, Nag1-S3, and Nag1-S6. The break represents values from 0.5 to 0.9. Relative expression levels were determined by qRT-PCR using the $\Delta \Delta C T$ method, with $\beta$-tubulin as a reference. Error bars indicate standard deviation from three independent experiments

alone. However, annotation of gene model predictions could potentially be improved using multiple methods performed in F. graminearum (Wong et al. 2011; Zhao et al. 2013). Our previous work also revised an erroneous annotation of gene model in $V$. dahliae based on sequence alignment and reverse-transcription PCR (Yang et al. 2013).

RNA-Seq is a useful method for revealing the transcriptional changes in eukaryotes (Cloonan et al. 2008; Metzker 2009; Davidson et al. 2012), and it is also an efficient tool for improving the gene models, discovering non-coding RNAs, and identifying novel transcript regions (Graveley et al. 2010; Li et al. 2011; Ren et al. 2012; Zhao et al. 2013). In this study, using bioinformatic methods and reverse-transcription PCR, we discovered a novel transcribed region in RNA-Seq data that was predicted to encode a novel annotated gene (Nag1) of $V$. dahliae. Interestingly, candidate Nag1 orthologs were only found in $A$. niger, and the functions of these proteins remain to be identified. Functional analysis of Nag1 by dsRNA-mediated gene silencing revealed that Nag1 is involved in fungal growth, conidial production, melanin biosynthesis, microsclerotia formation, and fungal virulence.

Nag1 is located in a secondary metabolism gene cluster in $V$. dahliae, and highly conserved homolog sequences of the whole gene cluster were found in the genome of $V$. alfalfae (Xiong et al. 2016). However, synteny of this whole gene cluster could not be found in $A$. niger and $F$. verticillioides. Although the homologs of VDAG_07930 and VDAG_07931 are adjacent in the $A$. niger genome, the Nag1 homolog is not located between them, and the VDAG_07928 homolog is located in another region (Additional file 6: Figure S6). In addition, the homologs of VDAG_07930,Nag1, and VDAG_07931 in the $A$. niger CBS genome do not belong to a secondary metabolism gene cluster predicted by the J. Craig Venter Institute (http://www.jcvi.org/smurf/index.php). Synteny of this secondary metabolism gene cluster region was only observed between $V$. dahliae and $V$. alfalfae, although single-gene homologs could be found in other fungal species. Regarding this specific secondary metabolism gene cluster, the backbone gene VDAG_ 07928 was the only PKS/NRPS hybrid gene predicted in the $V$. dahliae genome, whereas different numbers of PKS/NRPS hybrid genes were observed in other fungal species (Khaldi et al. 2010). Importantly, functional analysis of $A C E 1$, the homolog of VDAG_07928 in M. ory$z a e$, revealed that it is required for recognition of the fungus by resistant hosts (Böhnert et al. 2004). And the results show that the product synthesized by the PKS/ NRPS hybrid gene cluster of $A C E 1$ is involved in plantpathogen recognition. Interestingly, deletion of $A C E 1$ in $M$. oryzae does not dramatically affect fungal pathogenicity, indicating that the secondary metabolite synthesized by $A C E 1$ and its gene cluster is not a key pathogenicity factor. In addition, a PKS/NRPS hybrid gene in Trichoderma virens is also involved in induced 
systemic resistance, and the putative secondary metabolite generated by the gene cluster is important for the fungus-plant interaction (Mukherjee et al. 2012). In this study, silencing of Nag1 led to a significant reduction of gene expression in the same gene cluster, and the backbone gene VDAG_07928 was almost not expressed in Nag1-silenced mutants. However, we observed a reduction in the pathogenicity of Nag1-silenced mutants, indicating that secondary metabolites synthesized by VDAG_07928 and its cluster might be important for fungal pathogenicity. These results suggested that PKS/ NRPS hybrid genes in different fungal species may play different roles.

Phenotypic observations revealed that Nag1-silenced mutants exhibited a significant reduction in microsclerotia formation, but Nag1 was not differentially expressed during microsclerotia formation as shown in Fig. 1a. As mentioned above, silencing of Nag1 resulted in dramatic reduction of gene expression in the same secondary metabolism cluster, and our previous transcriptomic analysis revealed that genes in this cluster from VDAG_ 07920 to VDAG_07929 were significantly up-regulated during microsclerotia formation, although VDAG_07930 and VDAG_07931 were excluded (Xiong et al. 2014). Thus, the reduction of microsclerotia formation in Nag1-silenced mutants might result from Nag1-induced down-regulation of gene expression from VDAG_07920 to VDAG_07931. In addition, the Nag1-silenced mutants shared many phenotypes with the $\Delta V d M c m 1$ mutant, e.g., the reduction in fungal growth, microsclerotia formation, fungal virulence, and melanin accumulation. Importantly, our previous work showed that the whole gene cluster from VDAG_07920 to VDAG_07931, including Nag1, was regulated by $V d M c m 1$. These results suggested that many defects of the $\Delta V d M c m 1$ mutant may be derived from down-regulation of this secondary metabolism gene cluster. Interestingly, the Nag1-silenced mutants also showed many common phenotypes with the VdPR3 (VDAG_09942 encodes a predicted protein) deletion mutants in $V$. dahliae which also showed reduction in fungal growth, conidial production, microsclerotia formation, melanin accumulation, and fungal pathogenicity (Zhang et al. 2015). Additionally, it had been reported that an APSES transcription factor, vst1, led to strong downregulation of the gene cluster comprising VDAG_07920 - VDAG_07931, and deletion of this gene showed significant defects in microsclerotia formation and melanin production (Sarmiento-Villamil et al. 2018).

\section{Conclusions}

In this study, we identified and characterized the functions of a novel annotated gene, Nag1, in $V$. dahliae. Our results showed that Nag1 is involved in fungal growth, microsclerotia formation, cell wall integrity, melanin biosynthesis and fungal virulence which will facilitate the genetic studies of pathogenicity and microsclerotia formation in $V$. dahliae.

\section{Methods}

\section{Strains and media}

$V$. dahliae XS11, isolated from smoke tree (Cotinus coggygria), was used as the wild-type strain throughout this study (Wang et al. 2013). The strain V. dahliae Ls17 (ATCC accession MYA-4575), isolated from lettuce in California (CA), was kindly provided by Dr. Steven J. Klosterman (USDA-ARS). Generally, all strains were grown on potato dextrose agar (PDA) plates at room temperature. To test the growth rate and conidia production, the strains were grown on PDA plates and the experiment was repeated three times. To assay the conidial germination, conidia were harvested from cultures grown in fresh liquid complete medium (CM) (Dobinson et al. 1997) by filtration through two layers of Miracloth (Calbiochem, Germany) and then grown for 2 days in liquid basal medium (BM) (Neumann and Dobinson 2003) with $150 \mathrm{rpm}$. The percentage of conidial germination was measured by randomly recording 100 conidia, and the experiment was repeated three times. For DNA or RNA extractions, cultures were prepared in liquid $\mathrm{CM}$. For stress response assays, all strains were grown on $\mathrm{CM}$ plates with or without $1.2 \mathrm{M} \mathrm{NaCl}, 1.2 \mathrm{M} \mathrm{KCl}$, $0.5 \mathrm{M} \mathrm{MgSO}_{4}, 10 \mu \mathrm{g} / \mathrm{mL} \mathrm{CFW}$ and $100 \mu \mathrm{g} / \mathrm{mL}$ Congo Red. To assay the sensitivity to $\mathrm{H}_{2} \mathrm{O}_{2}$, a $5 \mathrm{~mm}$ filter paper disk was placed on the $\mathrm{CM}$ plates containing $10^{6}$ spores and then $5 \mu \mathrm{L} 5 \%$ or $15 \%(\mathrm{v} / \mathrm{v}) \mathrm{H}_{2} \mathrm{O}_{2}$ were dropped onto the filter paper disk as described previously (Molina and Kahmann 2007), and the experiment was repeated three times with three repetitions. The growth inhibition induced by the $\mathrm{H}_{2} \mathrm{O}_{2}$ was measured after 2 days of incubation at room temperature. To stimulate microsclerotia formation in vitro, $10^{5}$ spores/ $\mathrm{mL}$ conidial suspension was spread over cellulose membranes (pore size $=0.22 \mu \mathrm{m}$ ) which were overlaid onto the BM as described previously (Xiong et al. 2014). To observe the microsclerotia formation, a part of the membrane was observed with scanning electron microscopy. To reveal the accumulation of melanin, mycelia were grown in Czapek-Dox salts medium $(3 \mathrm{~g} / \mathrm{L}$ sodium nitrate, $0.5 \mathrm{~g} / \mathrm{L} \mathrm{KCl}, 0.5 \mathrm{~g} / \mathrm{L} \mathrm{MgSO}_{4} \cdot 7 \mathrm{H}_{2} \mathrm{O}, 1 \mathrm{~g} / \mathrm{L} \mathrm{K}_{2} \mathrm{HPO}_{4}$, $0.01 \mathrm{~g} / \mathrm{L} \mathrm{FeSO} 4 \cdot 7 \mathrm{H}_{2} \mathrm{O}$ ) (Bailey et al. 1997) supplemented with $3 \%$ sucrose.

\section{Construction of silencing vectors and transformation}

The putative ORF of Nag1 was amplified with primers 5/6. A 417 bp fragment of Nag1 was amplified from the cDNA of $V$. dahliae XS11 with primers $7 / 8$, which was then ligated into the pSilent-Dual1 (pSD1, which was 
bought from The Fungal Genetics Stock Center) that was digested with SmaI, named pSD1-Nag1. The pSD1Nag1 was introduced into the protoplasts of $V$. dahliae XS11 (Wang et al. 2013). Transformants were selected on TB3 medium (1 L: $3 \mathrm{~g}$ yeast extract, $3 \mathrm{~g}$ casamino acids, $20 \%$ sucrose, $0.7 \%$ agar for solid medium) with $50 \mu \mathrm{g} / \mathrm{mL}$ geneticin (Sangon, China).

\section{Sequence and data analysis}

The RNA-Seq coverage data were visualized using Integrative Genomics Viewer (Robinson et al. 2011). Sequence of Nag1 was acquired from $V$. dahliae genome database in Joint Genome Institute (JGI) (Klosterman et al. 2011). The putative ORFs were predicted by ORF Finder in National Center for Biotechnology Information (NCBI). The Nag1 homologs in other fungal species were identified using the BLASTP and BLASTN programs with default parameters in each genome database in JGI. Amino acid sequence alignments were performed with ClustalX2.0 (Larkin et al. 2007). Phylogenetic tree was constructed with MEGA 6.0 (Tamura et al. 2013) using neighborjoining method and the bootstrap test was replicated 1000 times. The domain architecture was visualized using InterPro (http://www.ebi.ac.uk/interpro/). Alignments of amino acid and nucleotide sequences were visualized using BioEdit (Hall 1999). Difference of measurement data was compared with single factor analysis of variance at $P \leq 0.05$ levels by using SPSS.

\section{Pathogenicity assays}

For pathogenicity tests, conidia were harvested from 7-day-old cultures grown in liquid CM by filtration through two layers of Miracloth and resuspended at $10^{6}$ conidia/mL in sterile distilled water. One-year-old smoke tree seedlings were inoculated by dipping their roots in the conidial suspensions for $10 \mathrm{~min}$. Control plants were mock-inoculated with sterile distilled water. All inoculated smoke tree seedlings were then replanted into the soil. Five smoke tree seedlings were tested per strain and the experiment was repeated three times. The inoculated plants were photoed after 45 days.

\section{qRT-PCR assays}

Total RNA was extracted using Trizol Reagent (Invitrogen, USA) and further purified with a PureLink RNA Mini Kit (Ambion, USA) and PureLink Dnase (Invitrogen, USA) according to the manufacturer's instructions. For qRT-PCR assays, cDNA was synthesized using oligo (DT) 18 primer and SuperScriApt III Reverse Transcriptase (Invitrogen, USA). qRT-PCR reactions were performed using SuperReal PreMix Plus (Tiangen, China) with the Applied Biosystems 7500 Real-Time PCR system. The $\beta$-tubulin gene was used as an internal reference for all qRT-PCR analyses. Relative expression levels were calculated using $2^{-\Delta \Delta \mathrm{Ct}}$ method (Livak and Schmittgen 2001). All primers used in this study were listed in Additional file 7: Table S1.

\section{Supplementary information}

Supplementary information accompanies this paper at https://doi.org/10. 1186/s42483-019-0039-1.

Additional file 1: Figure S1. Translation of the nucleotide sequences into amino acid sequences with BioEdit. (JPG 927 kb)

Additional file 2: Figure S2. Multiple nucleotide sequence alignment of Nag1 and its homolog sequences from other fungal species. Nucleotides over 50\% identity were shade in black color. (JPG 3317 kb)

Additional file 3: Figure S3. Conidial production of WT, Nag1-S3 and Nag1-S6 after grown in liquid CM. The turbidity represents the quantitative of conidial production. (JPG $419 \mathrm{~kb}$ )

Additional file 4: Figure S4. Impact of Nag1 silencing on cell wall integrity. a Colony morphology of WT, Nag1-S3 and Nag1-S6 after grown 10 days on $\mathrm{CM}$ or $\mathrm{CM}$ containing $1.2 \mathrm{M} \mathrm{NaCl}, 1.2 \mathrm{M} \mathrm{KCl}, 0.5 \mathrm{M} \mathrm{MgSO}_{4}$,

$10 \mu \mathrm{g} / \mathrm{mL}$ CFW and $100 \mu \mathrm{g} / \mathrm{mL}$ Congo red. $\mathbf{b}$ The relative growth rate of WT, Nag 1-S3 and Nag1-S6 in response to stress conditions. The \% growth was determined by using radial growth of treated samples divided the radial growth of untreated controls (100). c The diagram shows the sizes of the inhibition zone after treated with 5 and $15 \% \mathrm{H}_{2} \mathrm{O}_{2}$. The size of inhibition zone was measured at $2 \mathrm{dpi}$. Different letters in (b) and (c) indicate significant differences at $P \leq 0.05$. (JPG $642 \mathrm{~kb}$ )

Additional file 5: Figure S5. Expression of Nag1 is regulated by the MADS-box transcription factor VdMcm1. a RNA-Seq coverage data showed the reduction in Nagl transcript abundance in the $\mathrm{VdMcm} 1$ deletion mutant relative to WT. The novel transcript is indicated by a dotted red box. $\mathbf{b}$ Relative expression level of $\mathrm{Nag} 1$ in the $\mathrm{VdMcm} 1$ deletion mutant. Relative transcript levels were determined by qRT-PCR using the $\Delta \Delta C T$ method, with $\beta$-tubulin as a reference. Error bars indicate standard deviation from three independent experiments. (JPG $358 \mathrm{~kb}$ )

Additional file 6: Figure S6. Identification of $\mathrm{Nag} 1$ homologs and its adjacent genes among different $A$. niger isolates. The black lines represent the corresponding homolog genes between $V$. dahliae and $A$. niger. The red crosses represent no homolog genes were found. Genes displayed in the same horizontal line denote that they are located in the same regions of the genome. (JPG $333 \mathrm{~kb}$ )

Additional file 7: Table S1. Primers used in this study. (XLSX 13 kb)

\section{Abbreviations}

CM: Complete medium; dsRNA: Double-stranded RNA; ORF: Open reading frame; PDA: Potato dextrose agar; pSD1: pSilent-Dual1; RNAi: RNA interference

\section{Acknowledgements}

Not applicable.

Ethical approval and consent to participate Not applicable.

\section{Authors' contributions}

DX performed the experiments, analyzed the data and wrote the manuscript. YW and $C T$ designed the experiments and revised the manuscript. All authors read and approved the final manuscript.

Funding

This study was funded by the Fundamental Research Funds for the Central Universities (BLX201703).

Availability of data and materials Not applicable. 


\section{Availability of data and materials}

Not applicable.

\section{Consent for publication}

Not applicable.

\section{Competing interests}

The authors declare that they have no competing interests.

Received: 19 August 2019 Accepted: 18 October 2019

Published online: 06 November 2019

\section{References}

Agrawal N, Dasaradhi PVN, Mohmmed A, Malhotra P, Bhatnagar RK, Mukherjee SK. RNA interference: biology, mechanism, and applications. Microbiol Mol Biol Rev. 2003;67:657-85.

Bailey BA, Jennings JC, Anderson JD. The $24-\mathrm{kDa}$ protein from Fusarium oxysporum f. sp. erythroxyli: occurrence in related fungi and the effect of growth medium on its production. Can J Microbiol. 1997;43:45-55.

Bell AA, Puhalla JE, Tolmsoff WJ, Stipanovic RD. Use of mutants to establish (+)-scytalone as an intermediate in melanin biosynthesis by Verticillium dahliae. Can J Microbiol. 1976;22:787-99.

Bennett JW, Chung KT. Alexander Fleming and the discovery of penicillin. Adv Appl Microbiol. 2001;49:163-84.

Böhnert HU, Fudal I, Dioh W, Tharreau D, Notteghem JL, Lebrun MH, et al. A putative polyketide synthase/peptide synthetase from Magnaporthe grisea signals pathogen attack to resistant rice. Plant Cell. 2004;16:2499-513.

Cloonan N, Forrest AR, Kolle G, Gardiner BBA, Faulkner GJ, Brown MK, et al. Stem cell transcriptome profiling via massive-scale mRNA sequencing. Nat Methods. 2008;5:613-9.

Cuomo CA, Güldener U, Xu JR, Trail F, Turgeon BG, Di Pietro A, et al. The Fusarium graminearum genome reveals a link between localized polymorphism and pathogen specialization. Science. 2007;317:1400-2.

Davidson RM, Gowda M, Moghe G, Lin H, Vaillancourt B, Shiu SH, et al. Comparative transcriptomics of three Poaceae species reveals patterns of gene expression evolution. Plant J. 2012:71:492-502.

Dobinson KF, Lecomte N, Lazarovits G. Production of an extracellular trypsin-like protease by the fungal plant pathogen Verticillium dahliae. Can J Microbiol. 1997:43:227-33.

Duressa D, Anchieta A, Chen D, Klimes A, Garcia-Pedrajas MD, Dobinson KF, et al. RNA-seq analyses of gene expression in the microsclerotia of Verticillium dahliae. BMC Genomics. 2013;14:607.

Eisenman HC, Frases S, Nicola AM, Rodrigues ML, Casadevall A. Vesicle-associated melanization in Cryptococcus neoformans. Microbiology. 2009;155:3860-7.

Eisenman HC, Mues M, Weber SE, Frases S, Chaskes S, Gerfen G, et al. Cryptococcus neoformans laccase catalyses melanin synthesis from both Dand L-DOPA. Microbiology. 2007;153:3954-62.

Fang Y, Klosterman SJ, Tian C, Wang Y. Insights into VdCmr1-mediated protection against high temperature stress and UV irradiation in Verticillium dahliae. Environ Microbiol. 2019;21:2977-96.

Fire A, Xu SQ, Montgomery MK, Kostas SA, Driver SE, Mello CC. Potent and specific genetic interference by double-stranded RNA in Caenorhabditis elegans. Nature. 1998;391:806-11.

Fox EM, Howlett BJ. Secondary metabolism: regulation and role in fungal biology. Curr Opin Microbiol. 2008;11:481-7.

Fradin EF, Thomma BPHJ. Physiology and molecular aspects of Verticillium wilt diseases caused by V. dahliae and V. albo-atrum. Mol Plant Pathol. 2006:7:71-86.

Graveley BR, Brooks AN, Carlson JW, Duff MO, Landolin JM, Yang L, et al. The developmental transcriptome of Drosophila melanogaster. Nature. 2010;471: 473-9.

Hall TA. BioEdit: a user-friendly biological sequence alignment editor and analysis program for windows 95/98/NT. Nucl Acids Symp Ser. 1999;41:95-8.

Keller NP, Turner G, Bennett JW. Fungal secondary metabolism - from biochemistry to genomics. Nat Rev Microbiol. 2005;3:937-47.

Khaldi N, Seifuddin FT, Turner G, Haft D, Nierman WC, Wolfe KH, et al. SMURF: genomic mapping of fungal secondary metabolite clusters. Fungal Genet Biol. 2010;47:736-41.

Khatri M, Rajam MV. Targeting polyamines of Aspergillus nidulans by siRNA specific to fungal ornithine decarboxylase gene. Med Mycol. 2007;45:211-20.
Klimes A, Dobinson KF, Thomma BPHJ, Klosterman SJ. Genomics spurs rapid advances in our understanding of the biology of vascular wilt pathogens in the genus Verticillium. Annu Rev Phytopathol. 2015;53:181-98.

Klosterman SJ, Atallah ZK, Vallad GE, Subbarao KV. Diversity, pathogenicity, and management of Verticillium species. Annu Rev Phytopathol. 2009:47:39-62.

Klosterman SJ, Subbarao KV, Kang S, Veronese P, Gold SE, Thomma BPHJ, et al. Comparative genomics yields insights into niche adaptation of plant vascular wilt pathogens. PLoS Pathog. 2011;7:e1002137.

Larkin MA, Blackshields G, Brown NP, Chenna R, McGettigan PA, McWilliam H, et al. Clustal W and Clustal X version 2.0. Bioinformatics. 2007;23:2947-8.

Li L, Chang SS, Liu Y. RNA interference pathways in filamentous fungi. Cell Mol Life Sci. 2010;67:3849-63.

Li Z, Zhang Z, Yan P, Huang S, Fei Z, Lin K. RNA-Seq improves annotation of proteincoding genes in the cucumber genome. BMC Genomics. 2011;12:540.

Livak KJ, Schmittgen TD. Analysis of relative gene expression data using real-time quantitative PCR and the 2(-Delta Delta C(T)) method. Methods. 2001;25: 402-8.

Matzke MA, Birchler JA. RNAi-mediated pathways in the nucleus. Nat Rev Genet. 2005;6:24-35.

Metzker ML. Sequencing technologies—-the next generation. Nat Rev Genet. 2009:11:31-46.

Molina L, Kahmann R. An Ustilago maydis gene involved in $\mathrm{H}_{2} \mathrm{O}_{2}$ detoxification is required for virulence. Plant Cell. 2007:19:2293-309.

Mukherjee PK, Buensanteai N, Moran-Diez ME, Druzhinina IS, Kenerley CM. Functional analysis of non-ribosomal peptide synthetases (NRPSs) in Trichoderma virens reveals a polyketide synthase (PKS)/NRPS hybrid enzyme involved in the induced systemic resistance response in maize. Microbiology. 2012;158:155-65.

Nakayashiki $\mathrm{H}$, Nguyen QB. RNA interference: roles in fungal biology. Curr Opin Microbiol. 2008;11:494-502.

Nelson PE, Desjardins AE, Plattner RD. Fumonisins, mycotoxins produced by Fusarium species: biology, chemistry, and significance. Annu Rev Phytopathol. 1993;31:233-52.

Neumann MJ, Dobinson KF. Sequence tag analysis of gene expression during pathogenic growth and microsclerotia development in the vascular wilt pathogen Verticillium dahliae. Fungal Genet Biol. 2003;38:54-62.

Nguyen QB, Itoh K, Van Vu B, Tosa Y, Nakayashiki H. Simultaneous silencing of endo-beta-1,4 xylanase genes reveals their roles in the virulence of Magnaporthe oryzae. Mol Microbiol. 2011;81:1008-19.

Nguyen QB, Kadotani N, Kasahara S, Tosa Y, Mayama S, Nakayashiki H. Systematic functional analysis of calcium-signalling proteins in the genome of the riceblast fungus, Magnaporthe oryzae, using a high-throughput RNA-silencing system. Mol Microbiol. 2008;68:1348-65.

Nosanchuk JD, Casadevall A. The contribution of melanin to microbial pathogenesis. Cell Microbiol. 2003;5:203-23.

Pan Q, Shai O, Lee LJ, Frey BJ, Blencowe BJ. Deep surveying of alternative splicing complexity in the human transcriptome by high-throughput sequencing. Nat Genet. 2008:40:1413-5.

Peng Z, Cheng Y, Tan BCM, Kang L, Tian Z, Zhu Y, et al. Comprehensive analysis of RNA-Seq data reveals extensive RNA editing in a human transcriptome. Nat Biotechnol. 2012:30:253-60.

Puhalla JE, Bell AA. Genetics and biochemistry of wilt pathogens. In: Mace ME, Bell AA, Beckman $\mathrm{CH}$, editors. Fungal wilt diseases of plants. New York: Academic Press; 1981. p. 145-92.

Ren S, Peng Z, Mao JH, Yu Y, Yin C, Gao X, et al. RNA-seq analysis of prostate cancer in the Chinese population identifies recurrent gene fusions, cancerassociated long noncoding RNAs and aberrant alternative splicings. Cell Res. 2012;22:806-21.

Roberts A, Pimentel H, Trapnell C, Pachter L. Identification of novel transcripts in annotated genomes using RNA-Seq. Bioinformatics. 2011;27:2325-9.

Robinson JT, Thorvaldsdóttir H, Winckler W, Guttman M, Lander ES, Getz G, et al. Integrative genomics viewer. Nat Biotechnol. 2011;29:24-6.

Romero-Martinez R, Wheeler M, Guerrero-Plata A, Rico G, Torres-Guerrero H. Biosynthesis and functions of melanin in Sporothrix schenckii. Infec Immun. 2000;68:3696-703.

Sarmiento-Villamil JL, Garcia-Pedrajas NE, Baeza-Montañez L, García-Pedrajas MD. The APSES transcription factor Vst1 is a key regulator of development in microsclerotium- and resting mycelium-producing Verticillium species. Mol Plant Pathol. 2018;19:59-76.

Shi-Kunne X, de Pedro Jové R, Depotter JRL, Ebert MK, Seidl MF, Thomma BPHJ. In silico prediction and characterisation of secondary metabolite clusters in 
the plant pathogenic fungus Verticillium dahliae. FEMS Microbiol Lett. 2019; 366:fnz081.

Singh S, Braus-Stromeyer SA, Timpner C, Tran VT, Lohaus G, Reusche M, et al. Silencing of Vlaro2 for chorismate synthase revealed that the phytopathogen Verticillium longisporum induces the cross-pathway control in the xylem. Appl Microbiol Biotechnol. 2010; 85:1961-76.

Soanes DM, Chakrabarti A, Paszkiewicz KH, Dawe AL, Talbot NJ. Genome-wide transcriptional profiling of appressorium development by the rice blast fungus Magnaporthe oryzae. PLoS Pathog. 2012;8:e1002514.

Stipanovic RD, Bell AA. Pentaketide metabolites of Verticillium dahliae. 3. Identification of (-)-3,4-dihydro-3,8-dihydroxy-1 (2h)-naphtalenone((-)vermelone) as a precursor to melanin. J Org Chem. 1976;41:2468-9.

Tamura K, Stecher G, Peterson D, Filipski A, Kumar S. MEGA6: molecular evolutionary genetics analysis version 6.0. Mol Biol Evol. 2013;30:2725-9.

Tran VT, Braus-Stromeyer SA, Kusch H, Reusche M, Kaever A, Kuhn A, et al. Verticillium transcription activator of adhesion Vta2 suppresses microsclerotia formation and is required for systemic infection of plant roots. New Phytol. 2014;202:565-81.

Wang E, Norred WP, Bacon CW, Riley RT, Merrill AH Jr. Inhibition of sphingolipid biosynthesis by fumonisins. Implications for diseases associated with Fusarium moniliforme. J Biol Chem. 1991;266:14486-90.

Wang Y, Xiao S, Xiong D, Tian C. Genetic transformation, infection process and GPCR quantification of Verticillium dahliae on smoke-tree Cotinus coggygria. Australas Plant Pathol 2013;42:33-41.

Wang Z, Gerstein M, Snyder M. RNA-Seq: a revolutionary tool for transcriptomics. Nat Rev Genet. 2009;10:57-63.

Wheeler MH, Tolmsoff WJ, Meola S. Ultrastructure of melanin formation in Verticillium dahliae with (+)-scytalone as a biosynthetic intermediate. Can J Microbiol. 1976;22:702-11.

Wilhelm S. Longevity of the Verticillium wilt fungus in the laboratory and field. Phytopathology. 1955:45:180-1.

Wong P, Walter M, Lee W, Mannhaupt G, Münsterkötter M, Mewes HW, et al. FGDB: revisiting the genome annotation of the plant pathogen Fusarium graminearum. Nucleic Acids Res. 2011;39:D637-9.

Xiong D, Wang Y, Ma J, Klosterman SJ, Xiao S, Tian C. Deep mRNA sequencing reveals stage-specific transcriptome alterations during microsclerotia development in the smoke tree vascular wilt pathogen Verticillium dahliae. BMC Genomics. 2014;15:324

Xiong D, Wang Y, Tian L, Tian C. MADS-box transcription factor VdMcm1 regulates conidiation, microsclerotia formation, pathogenicity and secondary metabolism of Verticillium dahliae. Front Microbiol. 2016;7:1192.

Yang X, Ben S, Sun Y, Fan X, Tian C, Wang Y. Genome-wide identification, phylogeny and expression profile of vesicle fusion components in Verticillium dahliae. PLoS One. 2013;8:e68681.

Zhang YL, Li ZF, Feng ZL, Feng HJ, Zhao LH, Shi YQ, et al. Isolation and functional analysis of the pathogenicity-related gene VdPR3 from Verticillium dahliae on cotton. Curr Genet. 2015;61:555-66.

Zhao C, Waalwijk C, de Wit PJGM, Tang D, van der Lee T. RNA-Seq analysis reveals new gene models and alternative splicing in the fungal pathogen Fusarium graminearum. BMC Genomics. 2013;14:21.

Ready to submit your research? Choose BMC and benefit from:

- fast, convenient online submission

- thorough peer review by experienced researchers in your field

- rapid publication on acceptance

- support for research data, including large and complex data types

- gold Open Access which fosters wider collaboration and increased citations

- maximum visibility for your research: over $100 \mathrm{M}$ website views per year

At BMC, research is always in progress.

Learn more biomedcentral.com/submissions 